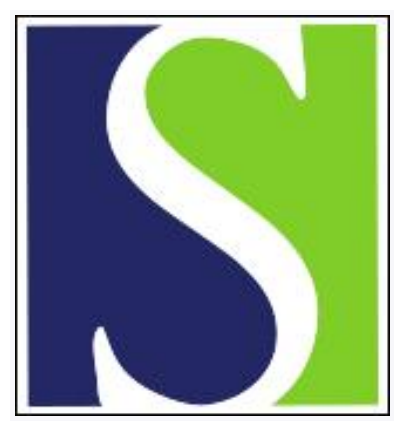

Scand J Work Environ Health 1975;1(3):193-198

https://doi.org/10.5271/sjweh.2846

Issue date: Sep 1975

Charcoal sampling method for determining the concentration of styrene in air.

by Kalliokoski P, Pfäffli P

The following article refers to this text: 1979;5(3):286-289

Key terms: air; charcoal sampling; charcoal tube; concentration of styrene; personal sampling; styrene

This article in PubMed: www.ncbi.nlm.nih.gov/pubmed/1228900

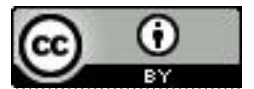




\title{
Charcoal sampling method for determining the concentration of styrene in air
}

\author{
by PENTTI KALLIOKOSKI, M.Sc. (Eng.), and PIRKKO PFÄFFLI, M.Sc. ${ }^{1}$
}

\begin{abstract}
KALLIOKOSKI, P. and PFÄFFLI, P. Charcoal sampling method for determining the concentration of styrene in air. Scand. $j$. work environ. \& health 1 (1975) 193-198. The vapors of styrene (vinylbenzene) were trapped on charcoal in a glass tube. Air from the worker's breathing zone was sucked through the tube by a battery-operated, modified, MSA personal sampling pump. The sampler and pumping system were worn by the worker. The styrene was eluted with dimethyl formamide and estimated by gas chromatography. The range and sensitivity of the method when sampling with a flow rate of $0.2 \mathrm{l} / \mathrm{min}$ during $I \mathrm{~h}$ were 5 to $1,500 \mathrm{ppm}$, and during $4 \mathrm{~h}$ they were 2 to $400 \mathrm{ppm}$. The recovery (accuracy) was over $90 \%$. The precision for the method, in terms of relative standard deviation, was $8.4 \%$.
\end{abstract}

Key words: charcoal tubes, personal sampling, styrene.

The rapid expansion of the reinforced plastic industry has caused potential risk of exposure to high concentrations of styrene vapor in factory air because many of the factories are small and lack adequate ventilation systems.

For measuring the styrene concentration of air, the following methods are available: absorption in a solvent like ethanol $(1,7,10,16)$; adsorption onto a solid material like silicagel or charcoal, followed by heating or solvent elution ( 2 , $3,4,5,6,12,13,15$ ); cold trapping (9); and grab sampling into empty tubes (15). Methods of analysis are based either upon ultraviolet absorption or the gas chromatography of styrene $(1,3,4,5,7,8,10,11$, $16)$; some also use colorimetry $(3,4,8)$. The purpose of the investigation was to test further the charcoal sampling procedure in order to obtain a useful method for styrene field studies.

1 Department of Industrial Hygiene and Toxicology, Institute of Occupational Health, Helsinki, Finland.

Reprint requests ta: Mr. Pentti Kalliokoski, Institute of Occupational Health, Haartmaninkatu 1, FIN-00290 Helsinki 29, Finland.

\section{MATERIALS AND METHODS}

\section{Principle of the method}

A known volume of air is drawn through a charcoal tube to trap the styrene present. The charcoal in the tube is transferred to a small test tube, containing dimethyl formamide, where the styrene is desorbed. The analysis is performed by gas chromatography.

\section{Apparatus and reagents}

Sampling device. A battery-operated personal sampling pump (a portable MSA pump, manufactured by the Mine Safety Appliances Co., Pittsburgh, Pa., U.S.A.) is connected via polyvinyl chloride tubing to the sampling tube. A lateral flow of air into the pump $(80 \%$ of total flow, fig. 1) permits the pump to be operated at a normal number of revolutions, and a stable flow rate of about $0.2 \mathrm{l} / \mathrm{min}$ is thus attained.

Preparation of the charcoal sampling tube. Activated coconut charcoal [Chemviron Pittsburgh (UK) activated carbon 
PCB] of 20/40 mesh is used. This grade gives an optimum between the flow resistance and absorption efficiency. The charcoal is reactivated by washing it with diluted hydrochloric acid and distilled water, drying it at $160^{\circ} \mathrm{C}$ for $4 \mathrm{~h}$, and by heating it at $450^{\circ} \mathrm{C}$ under the flow of nitrogen for $1 \mathrm{~h}$. A tube with a $7-\mathrm{mm}$ outer diameter is easily connected to the pump via a plastic hose. The tube is packed with $200 \mathrm{mg}$ (must be weighed) of reactivated charcoal and retained with small plugs of glass wool. The charcoal layer must be tight enough to avoid a change in the pressure drop across the tube and therefore also a change in the flow rate during the sampling. The tubes must be sealed with plastic stoppers.

Gas chromatography. The gas chromatograph is equipped with a flame ionization detector and a $0.5 \mathrm{~m} \times 4 \mathrm{~mm}$ glass column packed with Carbowax 20M, $10 \%$, on Cromosorb W (acid washed, silanized, $80 / 110$ ). The column is operated at $120^{\circ} \mathrm{C}$. The temperature of the injector is maintained at $200^{\circ} \mathrm{C}$. Amplifier sensitivity is set at one-sixteenth of the maximum.

Other equipment. Ten-milliliter test tubes (Kimax), which can be sealed with caps containing polyester-lined silicone rubber septa, are used; also microliter syringes, pipettes, and volumetric flasks.

Reagents. Styrene and dimethyl formamide, both of chromatographic quality, are used along with $1 \mathrm{~N}$ hydrochloric acid. The gases are nitrogen, hydrogen, and compressed air.

\section{Sampling}

A personal sampling pump is mounted on the back of the worker on a belt around the waist; it is connected to the sampling tube by tubing. The sampling tube is fastened with a piece of fabric tape and a safety pin to the worker's shoulder so that samples can be taken from the breathing zone.

The flow of the sampling device is calibrated with a wet test meter (Lange Gelsenkirchen). During the sampling procedure the charcoal tube can be changed when necessary. The sampling time for every single tube should be determined accurately with a seconds counter.

\section{Elution and analysis}

For the analysis the contents of the sampling tubes are emptied into the $\mathrm{Ki}$ max tubes by pushing with a metal wire. Tubes containing $5 \mathrm{ml}$ of solvent (dimethyl formamide) are capped and left standing overnight. The next day a 1-microliter portion of the eluted solution is examined by gas chromatography.

Estimation of the quantity of styrene is performed by comparing the solution with a standard solution containing known amounts of styrene in $5 \mathrm{ml}$ of solvent (dimethyl formamide) and $200 \mathrm{mg}$ of reactivated charcoal from the batch used in the test tubes. Standards must also be kept standing overnight.

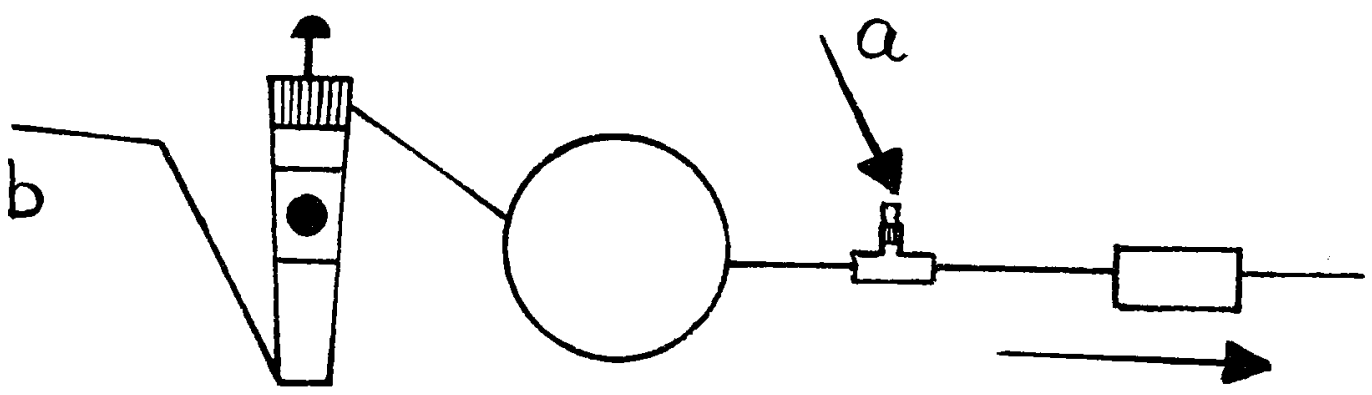

Fig. 1. The MSA personal sampling pump was modified at point a, at which a T-piece of plastic capped with a rubber stopper was added on the line. An injection needle with an inner diameter suitable to let $80 \%$ of the air flow pass through the stopper and permit only $20 \%$ to pass through the whole line was inserted in the stopper. The charcoal tube was connected at point $b$. 


\section{Experimental arrangements}

The initial air sample for the test is prepared in either polyester/aluminium-laminated bags or the exposure chamber, and the concentration is checked first directly in a gas form with a gas sampling loop in the gas chromatograph. In all of the tests a measured volume of air is sampled along the charcoal tubes, which are then desorbed and analyzed as the method describes.

\section{RESULTS}

\section{Charcoal tubes}

The adsorption efficiency of reactivated charcoal was tested for the possibility of overloading in sampling situations. One sampling tube proved capable of adsorbing up to $70 \mathrm{mg}$ of styrene at a sampling rate of $0.2-0.3 \mathrm{I} / \mathrm{min}$. During the loading it was possible to use the same tube for over $4 \mathrm{~h}$ without any significant loss (table 1).

Storing the capped samples seemed to cause no error. Sampling tubes $(n=40)$, prepared as described earlier, with the same initial $4.7 \mathrm{mg}$ concentration were stored in an identical way from 1 to 7 days, one-half at room temperature and the other half at a temperature of $4^{\circ} \mathrm{C}$. During the period two tubes of those stored at room temperature and two of those stored at a temperature of $4^{\circ} \mathrm{C}$ were analyzed daily. The same initial concentration [mean (M) \pm standard deviation $(\mathrm{SD})=4.7 \pm 0.1 \mathrm{mg}]$ was found in all analyses.

\section{Sampling pumps}

The flow rates and their precision with the modified MSA pumps with charcoal tubes on the line (at position 1 of the rotameter) had a mean of $226 \pm 27$ (SD) $\mathrm{ml} /$ min; thus the relative SD was $\pm 12.8 \%$ when 100 calibrations were made with 10 separate sampling sets. (When the three worst pumps were rejected, the relative $\mathrm{SD}$ was $\pm 8.1 \%$.) Using only the calibrations of the sampling set in question further diminished the error of flow rate and thus that of the volume collected (table 2).

The irregular movements of a pump on a worker's back (while a worker was moving and bending, even rapidly) did not seem to affect the flow rate remarkably. When the position of pump number 1 (connected to a charcoal tube) in table 2 was (a) upright, (b) at a $45^{\circ}$ angle, (c) on its side, (d) upside down, or (e)

Table 1. The effect of a long sampling period was tested by spooling the samples $1-3 \mathrm{~h}$ with fresh air.a

\begin{tabular}{|c|c|c|c|c|c|c|}
\hline $\begin{array}{l}\text { Number } \\
\text { of } \\
\text { tests }\end{array}$ & $\begin{array}{c}\text { Sampled } \\
\text { amount } \\
\text { of styrene } \\
\text { mg }\end{array}$ & $\begin{array}{c}1 \mathrm{~h} \\
\text { Leak during } \\
\text { sampling } \\
\% \pm \text { rel. SD }\end{array}$ & $\begin{array}{l}2 \mathrm{~h} \\
\text { Leak after } \\
\text { spooling } \\
\text { for } 1 \mathrm{~h} \\
\% \pm \text { rel. } \mathrm{SD}\end{array}$ & $\begin{array}{l}3 \mathrm{~h} \\
\text { Leak after } \\
\text { spooling } \\
\text { for } 2 \mathrm{~h} \\
0 \text { 土 rel. SD }\end{array}$ & $\begin{array}{c}4 \mathrm{~h} \\
\text { Leak after } \\
\text { spooling } \\
\text { for } 3 \mathrm{~h} \\
\% \pm \text { rel. SD }\end{array}$ & $\begin{array}{l}\text { Level in the first } \\
\text { initial tube after } \\
\text { a } 3-\mathrm{h} \text { air flow } \\
\text { along the tube } \\
\% \text { trel. SD }\end{array}$ \\
\hline 30 & $1-30$ & - & & & & \\
\hline 6 & $14-27$ & - & $2.8 \pm 2.2$ & $1.8 \pm 1.4$ & $1.2 \pm 0.8$ & $94.2 \pm 4.3$ \\
\hline 9 & $30-50$ & - & & & & \\
\hline 4 & $60-66$ & - & $2.6 \pm 3.1$ & $1.0 \pm 0.6$ & $1.6 \pm 0.9$ & $94.8 \pm 1.7$ \\
\hline 10 & $70-80$ & $2.6 \pm 2.2$ & & & & \\
\hline 5 & $80-90$ & $11.8 \pm 8.0$ & & & & \\
\hline 6 & $90-100$ & $24.8 \pm 10.7$ & & & & \\
\hline
\end{tabular}

a Two consecutive tubes: The first one contained the sample; the other one was changed every hour. The first tube was sampled for $1 \mathrm{~h}$ with the flow rate at $0.2-0.61 / \mathrm{min}$ from the exposure chamber, in which the concentration was $4.66 \mathrm{mg}$ styrene/1 (1,120 ppm). Every tube was analyzed separately. 
Table 2. Calibrations of ten sampling sets.

\begin{tabular}{lccc}
\hline $\begin{array}{l}\text { Pump } \\
\text { number }\end{array}$ & $\begin{array}{c}\text { Number } \\
\text { of tests }\end{array}$ & $\begin{array}{c}\text { Mean } \pm \mathrm{SD} \\
\text { of flow rate } \\
\mathrm{ml} / \mathrm{min}\end{array}$ & $\begin{array}{c}\text { Relative } \\
\text { SD }\end{array}$ \\
\hline & & & \\
1 & 10 & $209 \pm 15$ & 7.2 \\
2 & 10 & $270 \pm 8$ & 3.1 \\
3 & 10 & $198 \pm 23$ & $11.7 \mathrm{a}$ \\
4 & 10 & $206 \pm 15$ & 7.0 \\
5 & 10 & $228 \pm 10$ & 4.6 \\
6 & 10 & $221 \pm 37$ & 16.8 \\
7 & 10 & $256 \pm 16$ & 6.1 \\
8 & 10 & $233 \pm 14$ & 6.2 \\
9 & 10 & $182 \pm 27$ & $15.1 \mathrm{a}$ \\
10 & 10 & $221 \pm 8$ & 3.4 \\
\hline
\end{tabular}

a A pump with a relative $\mathrm{SD}$ of over 10 would not be used.

Table 3. The effect of acetone, present in the ambient air, on styrene sampling in two consecutive tubes (30 samples measured).

\begin{tabular}{lcc}
\hline Substance & $\begin{array}{c}\text { Measured } \\
\text { concentration } \\
\text { in air } \\
\text { (ppm } \pm \text { SD) } \\
\text { Tube 1 }\end{array}$ & $\begin{array}{c}\text { Measured } \\
\text { concentration } \\
\text { in air } \\
\text { (ppm } \pm \text { SD) } \\
\text { Tube 2 }\end{array}$ \\
\hline Styrene & $175 \pm 118$ & - \\
Acetone & $51 \pm 22$ & $11 \pm 7$ \\
\hline
\end{tabular}

swinging, the mean flow rate was $197 \pm$ 14 (SD) $\mathrm{ml} / \mathrm{min}$ (relative $\mathrm{SD} \pm 7.1 \%$ ) for 10 calibrations in each position.

\section{Desorption}

Dimethyl formamide desorbed $72.3 \pm 4.1$ (rel. SD) $\%$ when it was compared to "pure" standards after the overnight stand. However, when the samples were compared to dimethyl formamide standards $(5 \mathrm{ml})$, which contained precisely the same $(200 \mathrm{mg})$ amount of charcoal from the same batch as the tests and which stood for the same length of time for the balance to appear between the charcoal and solution, the desorption efficiency was found to be $100.2 \pm 0.9$ (rel. SD) $\%$. The presence of glass wool plugs did not cause any error.
Gas chromatographic analysis

The gas chromatographic analysis of the solutions at the concentration levels used (from 0.5 to $5 \mathrm{mg}$ styrene in $5 \mathrm{ml}$ of solvent) for dimethyl formamide gave a relative $\mathrm{SD}$ of $2.1 \%$ with injections of $1 \mu l(\mathbf{n}=10)$. Higher concentrations must be diluted to this level. The minimum amount of styrene detectable in the gas chromatography was $10 \mathrm{ng}$ for $1 \mu \mathrm{l}$ injection. The analyzing time of 20 min was shortened to $5 \mathrm{~min}$ with the backflush technique in order to remove the effect of the dimethyl formamide.

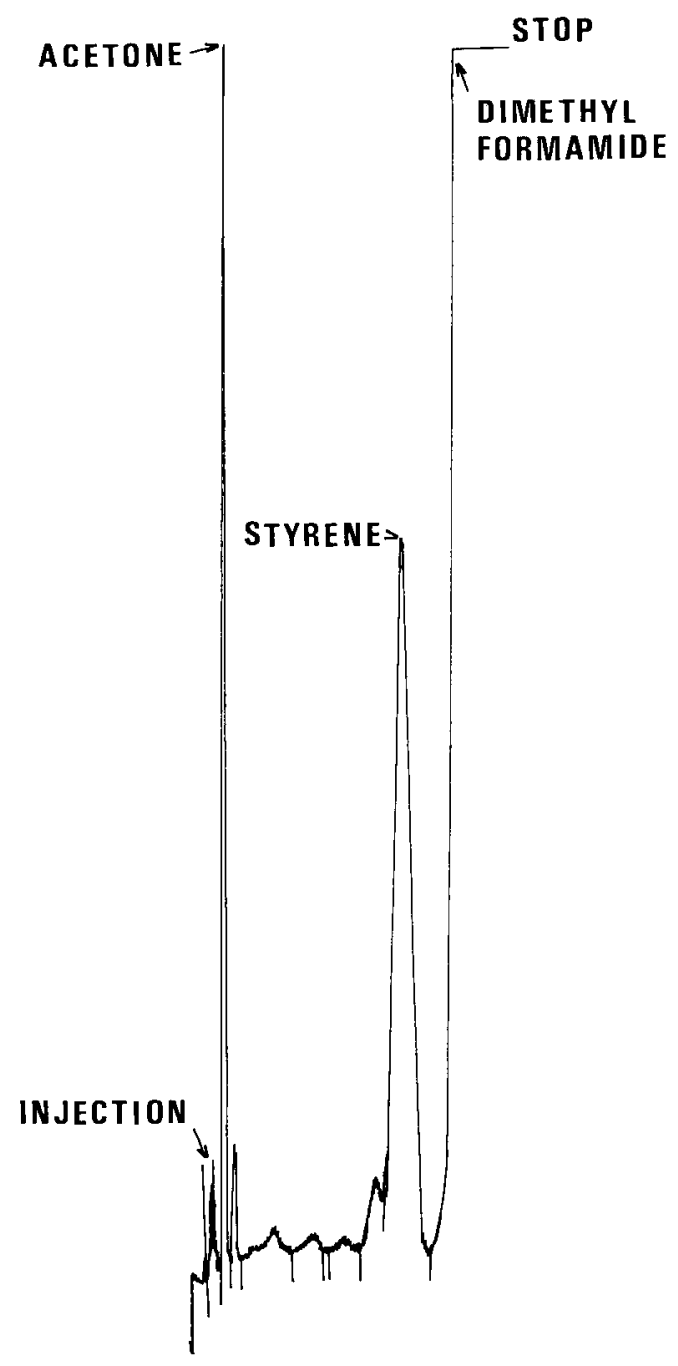

Fig. 2. A gas chromatognam of styrene analysis. 


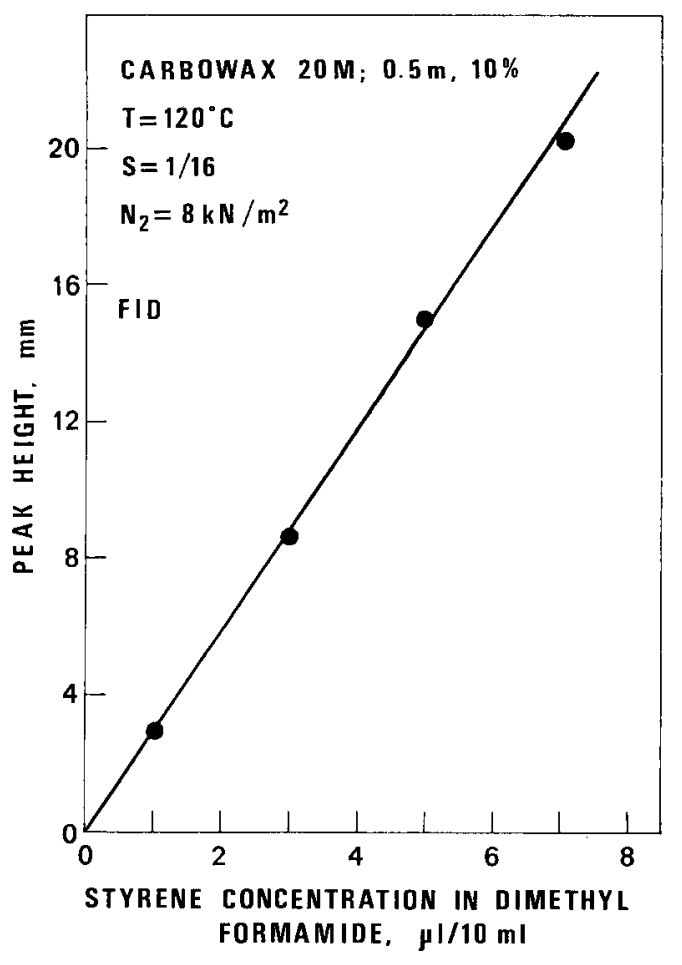

Fig. 3. Standard curve of styrene analysis.

\section{Interferences}

The appearance of other solvents simultaneously in the ambient air may interfere with the sampling and analyzing of styrene. Depending on their concentration and polarity as compared to those of styrene, the solvents take a part of the capacity of charcoal. They also give disturbing peaks in the gas chromatography.

Acetone, which is used for cleaning purposes when polyester plastics are made, seems not to be able to displace styrene from the charcoal because it obviously has a more polar character (14) than that of styrene and charcoal (table 3 ).

In gas chromatographic analyses the interferences can be eliminated by operating with different columns or column temperatures. The retention time of acetone differs, however, so much from that of styrene that there is no trouble in separating the two in gas chromatography (fig. 2).

\section{DISCUSSION}

Based on the results of the study, it may be concluded that the method is specific for styrene (fig. 2 and 3), its concentration range is large, and the recovery is better than $90 \%$ (for the whole method the relative SD is $\pm 8.4 \%$ ). As a desorption solvent dimethyl formamide is safer than the often-used carbon disulfide because it has a lower volatility. The greatest source of error is the flow rate measurement, which causes errors in sample volume determination. In spite of this fact the charcoal method provides a simple, inexpensive technique for the personal sampling of styrene.

\section{ACKNOWLEDGMENT}

The authors wish express their thanks to Ms. Pirjo Jylhä, Ms. Leila Valtonen, and Mr. Paavo Mäkelä for their technical assistance.

\section{REFERENCES}

1. BABINA, M. D. Spektrofotometritseskoe opredelenie stirola i benzaldegina pri sovmestnom prisutstvii v vozhude. Gig. sanit. 34 (1969) 105-106.

2. COOPER, C. V., WHITE, L. D. and KUPEL, R. E. Qualitative detection limits for specific compounds utilizing gas chromatographic fractions, activated charcoal and a mass spectrometer, Am. ind. hyg. assoc. $j$. 32 (1971) 383-386.

3. DUTKIEWICZ, T. and BLOCHOWICZ, A. Determination of styrene in air. Ann. acad. med. lodz. (1967) 205-212, Chem abstr. 70 (1969) $14223 \mathrm{~g}$.

4. DUTKIEWICZ, T. and BLOCHOWICZ, A. New colorimetric method for the determination of styrene in air. Chem. anal. (Warsaw) 13 (1968) 299-303, Chem, abstr. 69 (1968) 61372 u.

5. FLICK, K. Beitrag zur Bestimmung der Styrol Arbeitsplatz Konzentration bei der Verarbeitung von Polyesterharzen. $A r$ beitsschutz (1971) 25-29.

6. FRAUST, C. L. and HERMANN, E. R Charcoal sampling tubes for organic vapor analysis by gas chromatography. Am ind. hyg. assoc. j. 27 (1968) 68-74.

7. HANSON, N. W., REILLY, D. A. and STAGG, H. E. The determination of toxic substance in air. W. Heffer \& Sons Ltd, Cambridge 1965. $181 \mathrm{p}$.

8. H. M. FACTORY INSPECTORATE. Meth- 
ods for the detection of toxic substances in air (Booklet no. 4). Her Majesty's Stationary Office, London $1972.16 \mathrm{p}$.

9. KLUYZKO, A. S. and VOVYANKO, I. I. Chromatographic determination of ethylbenzene and styrene in air. Gig naselennykh mest (1967) 129-131, Chem. abstr. 70 (1969) 60572 t.

10. LEITHE, W. Analysis of air pollutants. Ann Arbor Science Publishers, Ann Arbor, Mich. 1971. $246 \mathrm{p}$.

11. ZUR MUEHLEN, T. Messungen von Styrol-Emissionen und Immisionen mit Hilfe der Gaschromatographie. Zentralbl. Arbeitsmed. 18 (1968) 41-43.

12. NATIONAL INSTITUTE FOR OCCUPATIONAL SAFETY AND HEALTH. NIOSH manual of analytical methods. U.S. Department of Health, Education and Wel- fare, Cincinnati, Ohio 1974, pp. 127, 1-11.

13. REID, F. H. and HALPIN, W. R. Determination of halogenated hydrocarbons in air by charcoal tube and gas chromatography. Am. ind. hyg. assoc. j. 29 (1968) $390-396$.

14. WEAST, R. C. Handbook of chemistry and physics. CRC Press Inc., Cleveland, Ohio 1974, pp. E64-E66.

15. WHITE, L. D., TAYLOR, D. G., MAUER, P. A. and KUPEL, R. E. A convenient optimized method for the analysis of selected solvent vapors in the industrial atmosphere. Am. ind. hyg assoc. j. 31 (1970) 225-232.

16. YAMAMOTO, R. K. and COOK, W. A. Determination of ethylbenzene and styrene in air by ultraviolet spectrophotometry. Am. ind. hyg. assoc. j. 29 (1968) 283-241.

Received for publication: 1975-05-30 